\title{
Training Regimes and Skill Formation in France and Germany: An Analysis of Change between 1970 and 2010
}

\author{
Benjamin Elbers* \\ Department of Sociology, Columbia University
}

Thijs Bol

Department of Sociology, University of Amsterdam

Thomas A. DiPrete

Department of Sociology, Columbia University

\begin{abstract}
How do educational systems prepare workers for the labor market? Stratification research has often made a distinction between two ideal-types: "qualificational spaces," exemplified by Germany with a focus on vocational education, and "organizational spaces," exemplified by France with a focus on general education. However, most studies that investigated this distinction did so by focusing only on the size of the vocational sector, not on whether graduates with a vocational degree actually link strongly to the labor market. Moreover, they often studied male workers only, ignoring potential gender differences in how school-to-work linkages are established. In this paper, we map the change in education-occupation linkage in France and Germany between 1970 and 2010 using an approach that can distinguish between changes in rates and changes in the structure of school-to-work linkages. Surprisingly, we find that the German vocational system in 1970 was not, on average, substantially more efficient in allocating graduates to specific occupations than the French system. This finding is a major departure from earlier results, and it shows that the differences between 1970's France and Germany, on which the qualificational-organizational distinction is based, are smaller than previously assumed. Partly, this is due to the fact that the female labor force was omitted from earlier analyses. We thus show that ignoring the female workforce has consequences for today's conception of skill formation systems, particularly because a large share of educational expansion is caused by an increase in female enrollment in (higher) education.
\end{abstract}

*be2239@columbia.edu 


\section{Introduction}

How do educational systems prepare students for the labor market? ${ }^{1}$ This question has been the focus of social scientists and policy-makers for a long time. In describing how countries establish a link between school and work, social scientists often rely on ideal-types of skill formation systems. An important distinction is made between systems that emphasize vocational training, where work and study are combined to prepare a student for work in a specific occupation or set of closely related occupations, and systems that emphasize general training, where education remains largely school-based and skill acquisition is more general. A large body of literature relies on this distinction, for example in trying to explain crossnational variation in youth unemployment, occupational mobility, status of the first job, or the length of job search (e.g., Breen 2005; Bol and Van de Werfhorst 2013), among other topics. The question of whether skill formation systems are adequately equipped to deal with rapidly changing skill requirements in today's labor markets (e.g., through automation or globalization) has also sparked policy debates in many countries.

One of earliest and influential studies in the school-to-work literature is Maurice, Sellier, and Silvestre's book The Social Foundations of Industrial Power (1986, MSS hereafter), in which they studied how French and German men made the transition from school to work. MSS concluded that the French and German skill formation regimes have radically different approaches in organizing the match between schools and labor markets. France is described as an organizational space, where workers are hired based on their level of general education. Germany, in contrast, is described as a qualificational space, where jobs are closely matched to workers with specific qualifications that they obtained within the educational system. In Germany, the linkage between the educational system and the labor market is tight, resulting in a skill-formation system where specialized educational credentials predict labor market standing relatively well. In France, on the other hand, this linkage is weaker, and educational qualifications hold less information about the labor market positions of workers: workers with the same educational background end up working in vastly different occupations. MSS influenced several scholars who used this distinction as an important component of their theoretical work on the macro-structure of educational systems (Kerckhoff 1995; Shavit and Müller 1998; Allmendinger 1989; Hall and Soskice 2001).

The extent to which the organizational-qualificational dimension adequately captures the major differences between educational systems, however, has been called into question by DiPrete et al. (2017). They introduced a new method for measuring school-to-work linkages, building on the idea that strong school-to-work linkages imply that occupations are educationally homogeneous. Surprisingly, the authors found that France and Germany differ less than expected in terms of how closely educational pathways and occupations

\footnotetext{
${ }^{1}$ This research was supported by NSF grant SES-1423828, in part by a Veni grant from the Netherlands' Organization for Scientific Research (451-15-001), and by a grant from the American Educational Research Association which receives funds for its "AERA Grants Program" from the NSF (NSF-DRL 1749275). Opinions reflect those of the authors and do not necessarily reflect those of AERA or NSF. We would also like to thank Louis-André Vallet, Martin Barnay, Irma Mooi-Reci, three anonymyous reviewers, and the participants of the conferences and workshops in Bern, Frankfurt, Bamberg, Berlin, Austin, and Torino. This study is based on data from Eurostat and other data sources. The responsibility for all conclusions drawn from the data lies entirely with the authors.
} 
are linked. When comparing similar educational pathways across the two countries (say, university-educated workers in health), the French skill formation system often performs equally well in leading graduates to occupations that are a good fit to their skills (see also Bol, Eller, et al. 2019) as the German qualificational space. Their analysis illuminated the fact that educational systems can differ both on a compositional dimension (the distribution of students across educational tracks), and in terms of their structure of association - the strength of linkage.

This similarity between the French and German skill formation system leads to a puzzle: If MSS were correct, then one or both countries must have changed. This would call into the question the quite static treatment of skill-formation systems in the literature. A second explanation for the puzzle is the treatment of gender in MSS. Their results are based only on the male labor force, while DiPrete et al. (2017) studied the whole labor force. We explicitly study potential gender differences, as generalizations about the two skill-formation systems may not be warranted when a large part of the labor force is disregarded.

This paper addresses this puzzle and maps how skill formation systems change by providing an empirical description of the possibly changing patterns of school-to-work linkages. We built upon earlier work by DiPrete et al. (2017), but introduce the dimension of time by focusing on the evolution of school-to-work linkages in France and Germany between 1970 and 2010. This requires the use of a method that is able to distinguish between compositional and structural changes, as in the last decades both France and Germany have seen educational expansion and an increase in the labor market participation of women-processes that are likely associated with changes in school-to-work linkages.

\section{Country-level ideal-types}

The study of skill formation systems has usually focused on country-level differences. Studies have classified educational systems along a number of dimensions (Allmendinger 1989), and this work was often influenced by MSS's qualificational-organizational distinction. A key aspect of this distinction is the focus on vocational specificity. In their comparative project, Shavit and Müller (1998) studied rates of vocational education (among other system characteristics) and their implications for the pathways that lead from school to work. Their key argument is that cross-national variation in how educational systems prepare students for the labor market is largely based on how many students are enrolled in vocational education:

[W]e distinguish between two ideal-typical regimes of school-to-work transitions, which, following Maurice, Sellier, and Silvestre, we label qualificational and organizational spaces. The qualificational space is characterized by a high rate of specific vocational education. More precisely, a large proportion of the graduating cohorts leave the educational system with specific skills and occupational identities. This is in contrast with organizational spaces where education is predominantly academic or general, and where occupational skills are learnt on the job or in courses taken after leaving school." (Müller and Shavit 1998, p. 9)

The consensus in the literature is that school-to-work linkages are stronger in skill-formation systems that rely on occupation-specific vocational education and fit the "qualificational 
space" ideal-type (e.g., Wolbers 2007; Breen 2005; Müller and Gangl 2003). Students leave the educational system well-prepared and find work in an appropriate occupation relatively quickly, often because they enter the labor market with relevant work experience. This also has consequences for career mobility, which is higher in organizational spaces (Haller et al. 1985; König and Müller 1986).

While this literature has established the importance of skill-formation systems for laterlife outcomes, we argue that the identification of countries with specific ideal-typical skillformation systems rests on assumptions that have rarely been tested empirically.

First, the approach implies the possibility of distinguishing vocational educational programs that provide specific skills from academic programs that provide general skills other through a credentialing requirement to work in specific occupations, as is typically the case with occupations that are called professions. However, it is rarely discussed how the skillcontent of educational programs can be measured. For instance, the UNESCO manual for the International Standard Classification of Education (ISCED) says virtually nothing about how skill content of vocational education is measured (OECD 2015, p. 65).

Second, even if it were possible to distinguish vocational and general programs, it would be an open empirical question whether specific skills are in fact associated with stronger school-to-work linkages. There is an implicit assumption that all vocational programs channel graduates to specific occupations, and so if there are more vocational graduates, the system will be more "occupation-specific." This focus on rates of vocational education asserts a substantive focus on the country as the unit of analysis: Rates are computed for the country as a whole; some countries are said to have vocational educational systems (Germany), and others are not (France or the U.S.). Given the considerable variation that is observed between different educational programs within the same country, we argue that a more fine-grained study of skill-formation systems is required.

\section{A structural approach}

We study the strength of school-to-work pathways as well as cross-national differences in their composition. We call this "linkage approach" a structural approach because (a) it does not rely on classifying programs as vocational or general, and (b) it measures the "success" of educational programs empirically by studying how closely a program is linked to specific occupations. The actual content of educational programs is difficult to ascertain, but a central characteristic of a "successful" vocational program is that it leads to one or a small set of specific occupations. This characteristic is jointly determined by educational content (e.g., length and intensity of the program, school-based vs. work-based programs) and by legal, cultural, and social characteristics of labor markets (e.g., occupational closure via licensing or collective bargaining agreements). We argue that a continuous, data-based measure of the strength of education-occupation linkage is more illuminating and empirically plausible than a binary, theoretically motivated classification (vocational/academic).

When comparing linkage across countries or within countries over time, a complication arises. Consider that someone who studied medicine in university is linked to the labor market asstrongly as agraduate of a car mechanic vocational program. Assume further that the countries differ in their educational composition: While both countries have the same 
proportion of car mechanic graduates, the first country has a higher proportion of medicine graduates. The impact on total linkage from these two educational categories will then be higher in the country with the higher proportion of medicine graduates. The difference between the two countries will be purely an effect of the different marginal distributions. On the other hand, the marginal distributions could be identical, but the linkage scores for different occupations could be different (say, in one country medicine graduates link strongly because they are almost all doctors, while in another country they are sometimes doctors and sometimes administrators or managers in hospitals). Thus, when comparing countries or the same country over time, there are always two potential sources of difference: differences in the marginal distributions of education and occupation, and differences in the patterns of association.

Differences in marginal distributions are important, but the "success" of a country's skillformation system lies in the effectiveness with which it can link educational systems and labor markets. Even if many German students are enrolled in vocational programs, this fact tells us very little about the extent to which they obtain occupation-specific education. Similarly, even if in France a much smaller proportion of workers takes a vocational degree, the extent to which that vocational degree channels school-leavers to the same occupation might be high. We thus talk about the strength of the association between specific educational outcomes and the occupational structure, and we use the term "structural linkage" for this component of total linkage. The linkage approach provides a clear contrast with existing studies that focus attention on compositional differences only, i.e. rates of vocational education.

\section{Patterns of change}

An important question in the literature on skill-formation systems is how they change. Neoinstitutionalism has argued that national educational systems were becoming increasingly standardized and focused on providing general education (Benavot 1983). The empirical evidence for this claim was the decline in the rate of secondary vocational education. The comparative project of Müller and Shavit (1998) came to a different conclusion. To be sure, the authors of the country-specific analyses saw change taking place to a greater or lesser extent in the countries they studied: For instance, France is described as a country that went through a dramatic expansion of secondary schools in the 1950s and 1960s (Goux and Maurin 1998), while Germany is described as a country with very stable educational institutions (Müller, Steinmann, and Ell 1998). However, these changes do not point universally in the direction of a decline of vocational education, refuting the neo-institutionalists' view of convergence. On the contrary, Müller and Shavit (1998) found that skill-formation systems are relatively 'fixed' in time.

In this paper, we revisit this question of change. We study both change in the educational and occupational marginal distributions (what we call compositional difference or change) as well as change in the structure of association between educational programs and occupations (what we call structural difference or change). We have several reasons for suspecting that not only the marginal distributions changed in important ways over recent decades, but also that the structure of association may have changed. 
First, DiPrete et al. (2017) have raised questions about the current conception of FrenchGerman educational differences. France at present has a smaller proportion of workers who were educated in programs that have tight linkage to the occupational distribution than does Germany. At the same time, many of France's educational programs have linkage that is as strong or stronger than in Germany. The differences between Germany and France, in other words, appear to involve both structural and compositional differences. However the study by DiPrete et al. (2017) did not involve historical data. It may thus be the case that either country has changed in the recent decades, and that the differences were more pronounced in the 1970s.

Second, from the contributions in Müller and Shavit (1998) and many other works studying the transformation of Western economies, we know that both the educational and the occupational distribution experienced considerable change in recent decades. In most countries, higher education has seen an enormous expansion, and many countries also saw an increase in vocational education. At the same time, economies have shifted towards the service sector, often accompanied by deindustrialization and the privatization of formerly state-owned companies. Educational expansion has likely increased school-to-work linkages in the aggregate, but the increasing supply of highly-educated workers may have led to a decrease in the structural part of linkage via processes related to "overeducation." Similarly, the shift towards the service sector, where jobs are potentially more loosely defined in terms of their educational requirements, may have also contributed to structural declines in linkage.

Lastly, two important but rarely-discussed aspects of MSS's study are that it focused only on large industrial firms and only on the male labor force. This latter point is also true for follow-up studies (e.g., Haller et al. 1985; König and Müller 1986). The point about gender was argued by Marry et al. (1998):

The majority of these studies have only been concerned with men [...], and one could ask whether the label "societal" is really appropriate for characteristics measured only for the masculine half of society. (p. 356, own translation)

Given the increase in female labor force participation rates since the 1970s, this critique has become even more important. In our analyses, we thus pay special attention to gender differences in the articulation of school-to-work linkages. The ideal-typical distinction that is still dominant today has been based only on the male labor force, and so we do not know to what extent "organizational" and "qualificational" spaces also exist for the full labor force.

\section{$5 \quad$ Analytical strategy}

\subsection{A measure of school-to-work linkage}

Our interest lies in the strength of the association between the educational system and the labor market as a function of time, operationalized here by the educational level and the field of study on the one hand (using the ISCED scheme), and current main occupations (ISCO-88) on the other hand. We use "field of study" here in a broad sense, referring to all education that is specific to an area of work, including vocational schooling, university degrees, but also the German Ausbildung in the dual system. The main analytical unit is the combination of educational level and field of study ("level-field"). 
To measure the strength of the link between education and occupation, we employ a multigroup segregation measure, as introduced by DiPrete et al. (2017). The link between the educational system and the labor market is tighter when educational qualifications predict the occupations of workers well. When school-to-work linkages are low, educational qualifications provide no information about the occupations of workers. To capture this idea, we use the Mutual Information Index $M$ (Mora and Ruiz-Castillo 2011; Theil and Finizza 1971).

We define $G$ as the set of combinations of $E$ ISCED levels and $F$ fields of study. $G$ are thus the "level-fields," which reflect the specialized educational qualifications that are available. To calculate $M$, consider a $G \times J$ contingency table, where each cell counts the number of workers that have one of level-field $G$ and one of occupation $J$. To simplify the notation, we transform the contingency table from a table of counts to a table of proportions (i.e., estimates of probabilities). Each cell's $p_{j g}$ represents the proportion of workers in occupation $j$ who were educated in level-field $g$, and therefore $\sum_{j} \sum_{g} p_{j g}=1$. We also define the marginal probabilities $p_{\cdot g}=\sum_{j} p_{j g}$ and $p_{j}$. $=\sum_{g} p_{j g}$, which simply reflect the overall level-field and occupational distributions. We define the conditional probability of being in occupation $j$, given a level-field $g$, as $p_{j \mid g}$.

We define $M(G ; J)$ as "total linkage," which measures the dependency between the levelfields and occupations contained within $G$ and $J$. Linkage is high for a specific level-field when the occupational distribution of that level-field deviates strongly from the overall occupational distribution. We call this the local linkage $L$ of level-field combination $g$, and define it as

$$
L_{g}=\sum_{j} p_{j \mid g} \ln \frac{p_{j \mid g}}{p_{j} .} .
$$

Local linkage will be minimized at zero when $p_{j \mid g}=p_{j}$. for all $j$. In other words, a levelfield is not linked to the labor market if the occupational distribution for workers that have this level-field is identical to the overall occupational distribution. The more strongly the occupational distribution for a level-field deviates from the overall occupational distribution, the higher the local linkage for this level-field. The possible maximum value for local linkage depends on the overall size of the smallest occupation. For instance, assume that the smallest occupation comprises $1 \%$ of the labor force. If all workers with level-field $g$ worked in only this occupation (i.e. $p_{j \mid g}$ is 1 for one $j$, but 0 for all other $j$ ), then local linkage would be maximized at $\ln \frac{1}{.01} \approx 4.6$.

To characterize overall linkage, $M$ is defined simply as the weighted average of the local linkage scores for all level-fields $G$ :

$$
M(G ; J)=\sum_{g} p_{\cdot g} L_{g} .
$$

This additive decomposition of $M$ is helpful in determining where in the educational distribution the linkage strength of a country originates. Further details can be found in the more extensive treatment by DiPrete et al. (2017). 


\section{$5.2 \quad$ Studying change}

The $M$ is not a margin-free measure of segregation, i.e., segregation may increase or decrease depending on changes in the marginal distribution of level-fields or occupations. This is immediately apparent from Eqs. 1 and 2. This means that changes in $M$ over time can arise through different mechanisms: either because of a change in the margins without any structural changes, or through a change in the structural association between level-fields and occupations. Given that we are interested in studying differences over time and across countries, we seek to isolate marginal and structural changes.

We adopt a procedure first proposed by Karmel and Maclachlan (1988) and extended by Elbers (2020). This procedure is based on the insight that the odds ratios of the contingency table are the only measure of association that does not change when the margins are transformed. Consider two $G \times J$ contingency matrices for the same country at different points in time, $t_{1}$ and $t_{2}$. To make a margin-free comparison, we adjust the margins of the contingency matrix at $t_{1}$ to be identical to those at $t_{2}$. This is achieved by the use of iterative proportional fitting (IPF), where first the row margins of $t_{1}$ are scaled towards those of $t_{2}$, and then the column marginals of the resulting table are scaled towards those of $t_{2}$. Repeating this process several times will transform the marginals of $t_{1}$ to approach the marginals of $t_{2}$, while preserving the odds ratios of the matrix as of time $t_{1}$. The process is repeated until the marginals are within $0.001 \%$ of the marginals at $t_{2}$. We call the resulting, counterfactual matrix $t_{1}^{\prime}$. We then repeat the IPF procedure, starting from matrix $t_{2}$, to arrive at matrix $t_{2}^{\prime}$. These two scenarios differ in the choice of the original matrix: One adjusts from $t_{1}$ forward towards $t_{2}$, while the other adjusts in a backward direction from $t_{2}$ to $t_{1}$.

Given the four matrices, we calculate $M\left(t_{1}\right)$ and $M\left(t_{2}\right)$ as the observed linkage at time $t_{1}$ and $t_{2}$. We also compute $M\left(t_{1}^{\prime}\right)$, as the adjusted $t_{1}$ linkage, which can be regarded as the counterfactual linkage at time $t_{2}$ if only the margins had changed to equal their values at time $t_{2}$. Because $M\left(t_{2}\right)$ and $M\left(t_{1}^{\prime}\right)$ have the same marginal distributions, they differ only in their association structure (i.e., the odds ratios). The same goes for $M\left(t_{1}\right)$ and $M\left(t_{2}^{\prime}\right)$. To arrive at a single estimate, we average the forward and backward scenarios (often called a Shapley decomposition):

$$
\begin{aligned}
M\left(t_{2}\right)-M\left(t_{1}\right) & =\overbrace{\frac{1}{2}\left(M\left(t_{2}\right)-M\left(t_{2}^{\prime}\right)\right)+\frac{1}{2}\left(M\left(t_{1}^{\prime}\right)-M\left(t_{1}\right)\right.}^{\Delta_{\text {marginal }}} \\
& +\underbrace{\frac{1}{2}\left(M\left(t_{2}\right)-M\left(t_{1}^{\prime}\right)\right)+\frac{1}{2}\left(M\left(t_{2}^{\prime}\right)-M\left(t_{1}\right)\right)}_{\Delta_{\text {structural }}}
\end{aligned}
$$

Another benefit of this approach is that it allows a further decomposition of the structural and the marginal component. The marginal change can be subdivided into two components: one component quantifies the contribution of changing educational marginals and one quantifies the contribution of changing occupational marginals. The structural component can be decomposed into the contributions of each individual level-field. We make use of this property by summing the contributions of the level-fields using ISCED categories and fields of study. Details are providedin Appendix A. 
The method described here can be used to compare any two $M$ measures, where " $t_{1}$ " and " $t_{2}$ " can stand either for different points in time or for different countries at the same time.

\subsection{Data}

The European Labor Force Survey (EU-LFS, Eurostat n.d.) is well suited for our purposes because it provides harmonized variables for educational levels, fields of study, and occupations. In the 2005 to 2010 datasets, educational levels and fields of study are coded in the ISCED-1997 scheme, and occupations are coded using ISCO-88 (3 digits). In 2011, the EU-LFS switched to ISCO-08, which is why we use only the years up until 2010. Because of the small sample size in Germany, we pool the samples for 2006-2007 and for 2008-2009. In the EU-LFS, no fields of study were recorded before 2005. For France, we additionally use the "Formation et Qualification Professionnelle" (FQP, INSEE/ADISP-CMH n.d.(b)) survey for 1970 and 1985, as well as the 1990-2002 series of the French Labor Force Survey (Enquête Emploi, INSEE/ADISP-CMH n.d.(a)). Here, fields of study are recorded consistently beginning in 1995. To increase the sample size, we pooled the years 1995-1997, 1998-2000, and 2001-2002. For West-Germany, we use the Public Use Files of the 1970 and 1987 censuses (RDC of the Federal Statistical Office and Statistical Offices of the Länder n.d.). ${ }^{2}$ We restricted all samples to the current active workforce aged 15 to $64^{3}$, leaving out students and the unemployed.

Educational level, field of study, and current main occupation were recorded in different schemes in many of these years. For educational levels, we used the official ISCED mappings to code degrees into the ISCED-1997 scheme (see Table 1). The EU-LFS does not provide a breakdown for category $3 a b$, which combines workers with general and specialized education. We therefore split this category using the field of study information: We code a worker as $3 a b \_v o c$ if a worker completed a professional or technological baccalauréat (maturity exam) in France or an Ausbildung (dual training) in Germany; we code as 3ab_gen for the general baccalauréat in France and the Abitur (maturity exam) in Germany. We merge $5 a$ and 6 $(\mathrm{PhD})$ because the latter is a small category and cannot be distinguished in earlier surveys. We also merge ISCED 0 and 1, because these two categories can not be distinguished in earlier years. In categories 1, 2 and $3 a b_{-}$gen, workers have obtained general education, while in all other categories workers have obtained specialized education (indicated by the presence of a field of study), be it either through dual training, vocational schooling, or in higher education. Programs classified as $5 b$ are advanced vocational programs on the verge of tertiary education, while programs in $3 c$ and $3 a b \_v o c$ are more often a mix of on-the-job training and school-based training.

Fields of study have been manually coded into ISCED fields of study (see Table 2). The crosswalks are found in Online Appendix 1. Except for the FQP survey in 1970, we were able to use proportional crosswalks to harmonize native occupational codings into ISCO88 (one of these crosswalks is constructed using data provided by BIBB 2006). To create a proportional crosswalk, we identified surveys where the native occupational scheme and ISCO-88 were coded for the same individuals. For each native code, we then calculated the

\footnotetext{
${ }^{2}$ The Mikrozensus cannot be used for our purposes, because up until 2004 it is missing the field of study for people who were trained in the dual system.

${ }^{3}$ We examined other age cutoffs (Online Appendix 3).
} 


\begin{tabular}{lll}
\hline Category & France & Germany \\
\hline ISCED 1 or less & Elementary education or less & Elementary education or less \\
\hline ISCED 2 & $\begin{array}{l}\text { Brevet, BEPC or some } \\
\text { secondary education }\end{array}$ & Hauptschul-/Realschulabschluss \\
\hline ISCED 3c & CAP, BEP, BP & \\
\hline ISCED 3ab_voc & Baccalauréat professionnel & $\begin{array}{l}\text { Lehrabschluss, short vocational } \\
\text { school }\end{array}$ \\
& Baccalauréat technologique & Abitur, Fachhochschulreife \\
\hline ISCED 3ab_gen & Baccalauréat général & Abitur/Fachhochschulreife and \\
\hline ISCED 4 & & Lehrabschluss \\
\hline ISCED 5b & DUT, BTS & Meister, Techniker, long \\
& infirmier, assistante sociale & vocational school (Fachschule, \\
& & e.g. in health) \\
\hline ISCED 5a/6 & DEUG, License, Maîtrise, & BA, Miplom, Magister, etc. \\
& Diplôme, etc. & Promotion \\
& DEA, Diplôme de docteur & \\
\hline
\end{tabular}

Table 1: ISCED-1997 and native degrees

Note: Adapted from official ISCED mappings for France and Germany (http://uis.unesco.org/en/ isced-mappings)

proportion of double-coded ISCO-88 codes. For instance, the French PCS-1982 code 3751 (Cadres de l'hotellerie et de la restauration) is coded in ISCO-88 as 122 (Production and operations department managers) in $58 \%$ of the cases, and 131 (General managers) in $42 \%$ of the cases. When we apply the crosswalk to our data, we randomly choose with a probability of .58 the ISCO code 122, and 131 otherwise. This process introduces uncertainties into our estimates, which are in practice very small (see Online Appendix 2).

\section{Results}

\subsection{Descriptives}

Table 2 provides descriptive statistics by year. Percentages are reported for gender and age groups, as well as for our three main variables of interest.

The tables confirm the well-known patterns of the changing demographics of labor force participation. Women's labor force participation increased from $37 \%$ to $48 \%$ in France and from $36 \%$ to $46 \%$ in Germany - always slightly below the French levels. The changes in the age structure reflect both an aging population and an increase in educational attainment. Many of those aged 15-24 in 1970 were already in the labor force, while in 2010 many in this age group are still in vocational or tertiary education, entering the labor market at older ages.

Of special interest are the dramatic changes in the educational structure. In Table 2, the effects of educational expansion are clearly visible, with increases in vocational (ISCED $3 a b \_v o c, 3 c$, and 4) and tertiary education and strong declines in the share of workers with a "general" field, i.e. ISCED levels 1, 2, and 3ab_gen. For both countries most of the expansion 


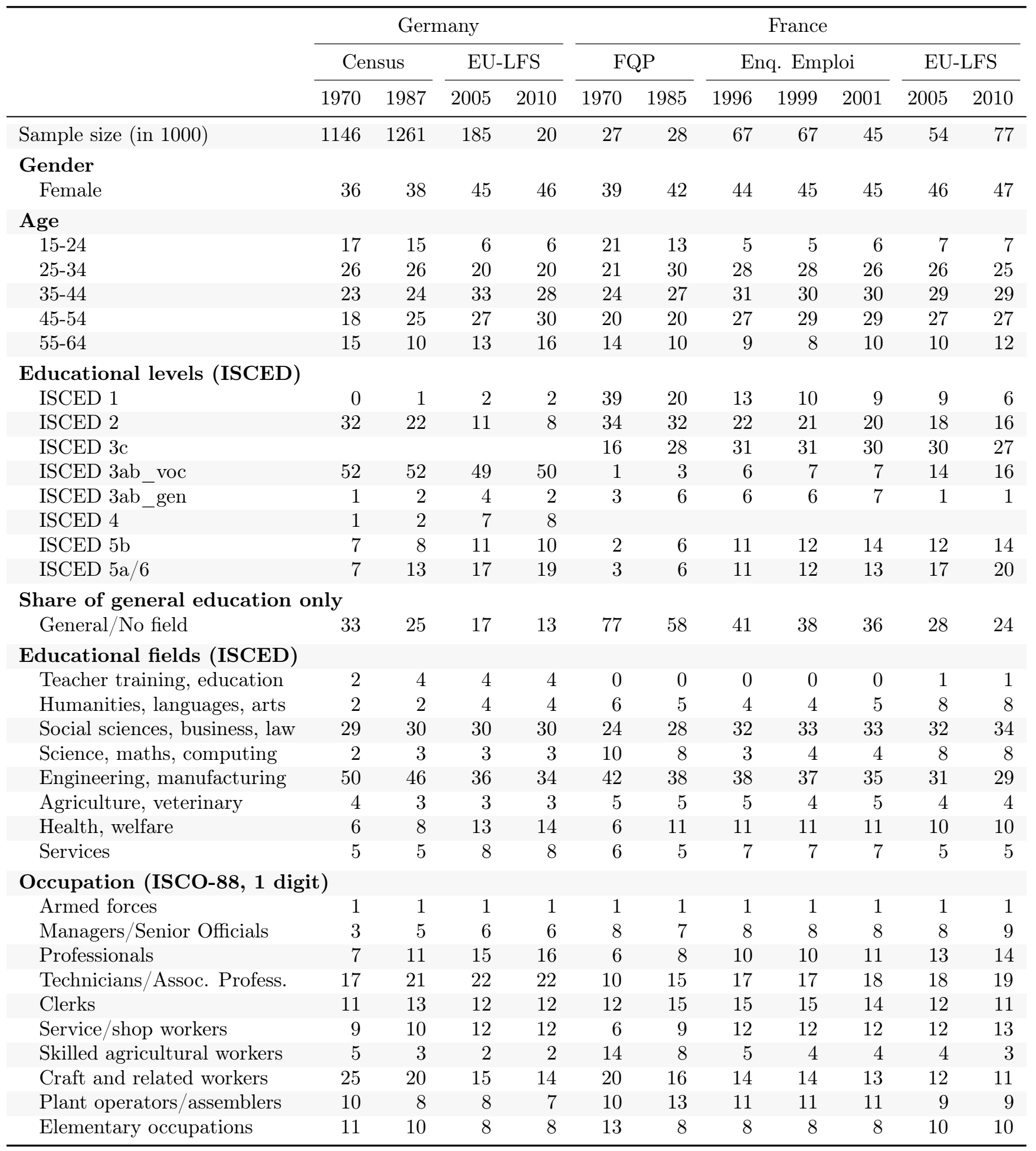

Table 2: Descriptive statistics by year 
of tertiary education was in higher tertiary education (university and post-graduate degrees, ISCED $5 a / 6$ ) instead of lower tertiary courses (ISCED $5 b$ ).

If we maintained a focus on rates of vocational education, then clearly the French skillformation system has changed enormously: for instance, the combined share of graduates in $3 c$ and $3 a b \_v o c$ has risen from $17 \%$ to $43 \%$. The numbers also show clear differences in the two countries' skill-formation systems. In 1970 Germany, roughly $60 \%$ of the labor force had undergone vocational education (ISCED 3ab_voc, 4, and 5b), compared to less than $20 \%$ in France. In 2010, France's educational distribution resembles Germany's distribution in 1970. The relative shares of both vocational and tertiary education in France have increased enormously, leading to a labor force in 2010 with over three quarters of the workers having some sort of specialized education, up from less than one quarter in 1970. This underscores the stability of the German skill formation system compared to a number of educational reforms in France that aimed to increase vocational and tertiary education levels (Day 2001; Brauns et al. 1999). This pattern of stability in Germany and change in France is a recurring theme in this paper.

Vocational education is traditionally focused on manufacturing and business degrees, which in both countries constitute the majority of degrees awarded. With deindustrialization and an increasing focus on service occupations, the relative share of manufacturing degrees has decreased markedly over time in both countries. The increasing diversity of vocational education is reflected by an increase in health, welfare, and services degrees. When comparing the distribution of fields of study between the countries, they show a roughly similar pattern.

The distribution of occupational major groups and the patterns of occupational change are similar in both countries, suggesting changes in the skill distribution of the labor force that are common to both economies. The growth has been concentrated in high- and medium skilled occupations (groups 1 to 5), while lower-skilled occupations have declined (groups 69). There are also some important differences between France and Germany that seem stable over time. In both 1970 and 2010, Germany had more workers in craft and professional occupations (groups 2, 3, 7), while France had more workers in agriculture, low-skilled, and management occupations (groups 1, 6, 9). This pattern is consistent with MSS's findings about the organization of work in the two countries. In France, the number of low-skilled workers and managers is higher, while Germany relies more on specialized, "medium-skilled" workers.

\subsection{Observed total linkage over time}

Figure 1 shows the strength of linkage for France and Germany both for the whole labor force, as well as for men and women separately. Each panel also contains a breakdown by younger (ages 15-34) and older workers (ages 50-64). The $M$ is measured for each year and gender-age-country combination separately and defined by applying eq. 2 to the matrix of level-fields and three-digit ISCO-88 occupations.

The absolute value of the $M$ is not strictly interpretable, as the values it can take depend on the dimensions of the contingency table. While an absolute interpretation is not possible, by harmonizing the data, we can compare the $M$ scores in terms of their relative differencescountries over time, between countries over time, or between genders. For this reason we will interpret the changes in $M$ as percentage differences. 

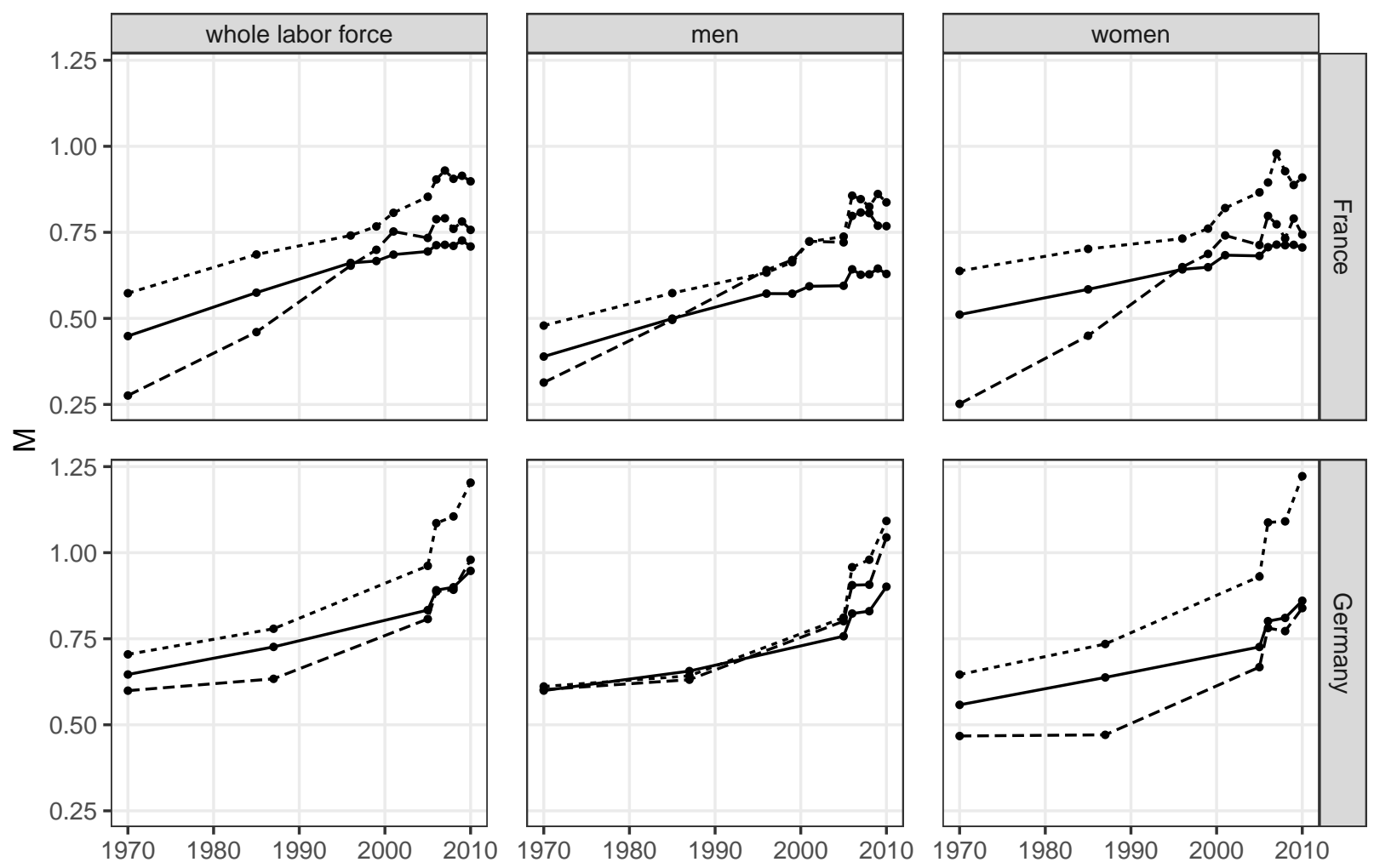

Age group — all ages $-\cdots \cdot 15-34 \quad--\cdot 50-64$

Figure 1: Aggregate linkage over time, by gender, age, and country 
Concentrating first on the whole labor force, Germany's $2010 M$ was about 38\% higher than France's. This is similar to the difference reported in DiPrete et al. (2017), who used different datasets. In 1970, Germany's $M$ was 50\% higher than France's. Since 1970, Germany's overall $M$ has increased by $56 \%,{ }^{4}$ and France's $M$ by $70 \%$, with most of this change occurring before 2000. In terms of total linkage, the countries have thus slightly converged over time.

The gender breakdown reveals that in both countries, the rate of linkage change has been similar for men and women. However, in Germany, men have slightly higher linkage than women, while in France the opposite is true. One reason for this could be the different gender-specific occupational composition of the French and German labor markets. A large share of the German male workforce is employed in the skilled trades and crafts, which tend to be well-linked. In France, in contrast, men are more often employed in clerical and service occupations that tend to be linked less strongly. ${ }^{5}$

A more striking pattern emerges when one takes into account the differences between age groups. Figure 1 shows that age differences in linkage are small for German men, while they are much larger for German women. Age group differences are larger for men in France than in Germany, but in France (just as in Germany), the age differences in linkage strength are stronger for women than for men. To put it differently, older women are in occupations that link less well than is the case for younger women in both countries, and this age gap is bigger for women than for men. However, the two countries differ in the pattern of change. In France, a visible convergence of linkage strength for older and younger workers has occurred in recent years for both men and women. In contrast, the linkage-strength gap between older and younger German women has not closed over the forty years covered by our data.

Finally, while the size of the age gap varies by country and gender, the relative pattern is similar and in the expected direction: Younger workers who have just begun their careers link more strongly than older workers with notably stronger age effects for women than for men. The small differences in linkage strength for older and younger German men suggests a relative stability of educational institutions across cohorts and a relatively minor impact of career mobility for the linkage strength of German male workers. In France, the temporal gains in linkage strength for younger workers may signal that educational reforms have shifted educational attainment towards more strongly-linking educational degrees. The even stronger upward shift for older male French workers may reflect the lagged effects of shifts for younger workers combined with career mobility patterns that produce higher linkage strength. The especially strong temporal gain in linkage strength for older female French workers may reflect changing implications of motherhood on their composition and occupational placement as well as lagged early career effects.

A pattern that is not easy to distill from Figure 1 is that cross-national variation in linkage highly depends on which gender one focuses on. Figure 2 sheds light on this issue and shows the difference in linkage between France and Germany by gender. When only taking men into account (Figure 2, left panel), our results seem to support MSS's main conclusions:

\footnotetext{
${ }^{4}$ Germany's $M$ showed an especially strong increase between 2005 and 2010 . We discuss possible reasons for this, as well as possible consequences for our later results in Online Appendix 4.

${ }^{5}$ We emphasize that the analysis only takes into account the employed population. Future research might address the question of how changing labor force participation rates by education have influenced school-to-work linkages, especially for women. We present a short analysis in Online Appendix 5.
} 

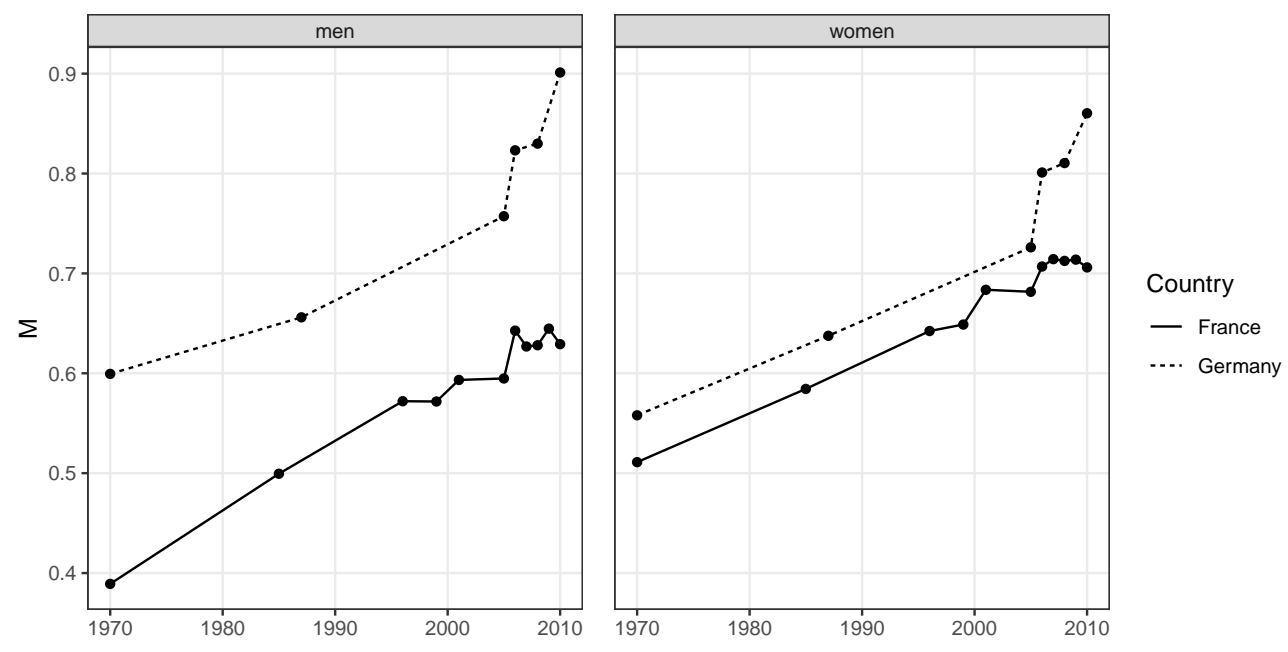

Figure 2: Gender-specific patterns of linkage

Germany provides a tighter school-to-work linkage that France. This conclusion is starkly different for women (right panel). Especially during the 1970s (the likely period of MSS's research), linkage for women is only slightly higher in Germany than it is in France and the similarities between the two countries are more striking than the differences. Combined with the results from Figure 1, our findings question a clear separation between the German and French skill formation systems. Are they indeed the two extremes of the ideal-typical distinction between qualificational and organizational spaces, or is this conclusion by MSS only applicable to part of the labor force?

Next, we use eq. 2 to study where the linkage strength in Germany and France originates. The full decomposition of local linkage scores gives 35 terms, one for each level-field. For a more parsimonious presentation, we sum the contribution of level-fields to the total $M$ by simplified ISCED levels, where we group tertiary education (ISCED $5 a / 6$ ), upper vocational/lower tertiary education $(5 b)$, vocational education $\left(3 a b \_v o c, 3 c, 4\right)$, and general education $\left(1,2,3 a b_{-} g e n\right)$. The four components are plotted separately by country-years in Figure 3. The percentage indicates the relative contribution towards total linkage strength, and it is instructive to compare this number to the proportion of the respective level among the labor force from Table 2.

In Germany, almost half of the total linkage strength in 1970 originates from upper secondary vocational education (ISCED levels $3 a b_{-} v o c / 3 c / 4$ ). Although only $7 \%$ of graduates had obtained tertiary education $(5 a / 6)$, this component accounts for $27 \%$ of total linkage strength. General education (i.e., ISCED 1/2/3ab_gen) comprised one third of Germany's labor force in 1970, but contributes only $13 \%$ to total linkage. In 2010, these relative contributions have changed only little, and seem to be mostly explained by changes in the relative proportions. France in 1970 was dominated by general education: $78 \%$ of the labor force had a general degree, and this group contributes $34 \%$ towards total linkage. While the other three components together constitute only a small share of the labor force, they contribute a considerable amount. Two thirds of France's linkage in 1970 originates from just $22 \%$ of the labor force. France's changing educational distribution is also reflected in a different pattern 

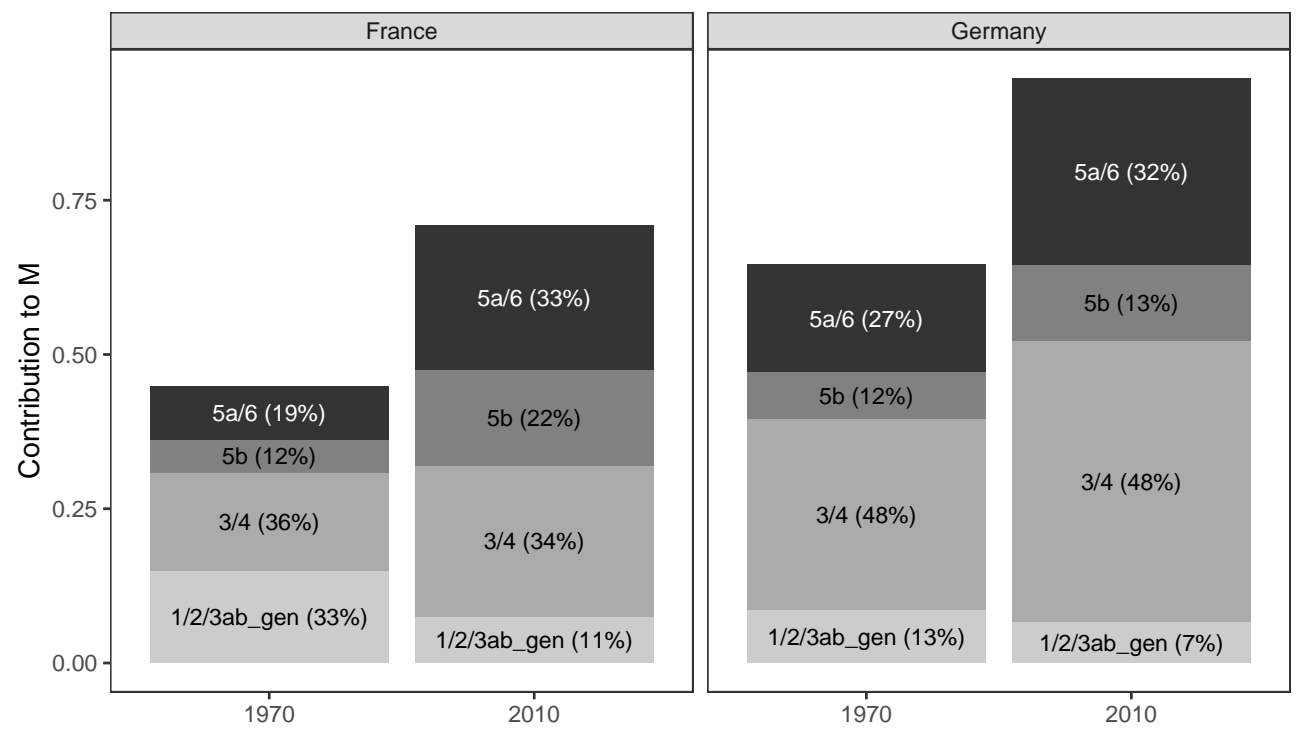

Figure 3: Decomposition of $M$ by ISCED levels

Note: ISCED $3 / 4$ refers to ISCED 3ab_voc, 3c, and 4.

of linkage: In 2010, general education contributes much less to linkage, and the contributions of ISCED 5 and 6 have grown considerably.

\subsection{Between-country differences: then and now}

As we noted above, stratification research has often equated high rates of vocational training with high vocational specificity and treated this as a structural feature of the country's educational system. Figure 3 already shows that this conclusion might not be justified: In France in 1970, vocational graduates were only a small share of the labor force, but this group linked strongly to the labor market. Thus, the internal structure of school-to-work linkages in France and Germany does not match the conventional wisdom about these two countries.

The findings presented so far have to be interpreted with caution, as they do not fully account for differences in the educational and occupational marginal distributions. Comparisons between countries and over time can be misleading when approached through Figure 3, because they combine structural and marginal differences. We now present decompositions that allow us to disentangle the possible sources of difference.

First, we apply eq. (3) to the differences between countries, both in 1970 and in $2010 .{ }^{6}\left(t_{1}\right.$ stands for Germany, and $t_{2}$ for France). The results are shown graphically in Figure 4, where the left panel decomposes the differences for the complete labor force, and the right panel contains results separately by gender. A negative score means that the French component is lower than the German component.

The top panel shows the raw difference in linkage between the two countries as observed in Figure 1. This total difference is decomposed into the three components shown in the

\footnotetext{
${ }^{6}$ From this section on, we combine ISCED categories $3 a b \_v o c, 3 c$, and 4 to achieve greater comparability between the two countries.
} 

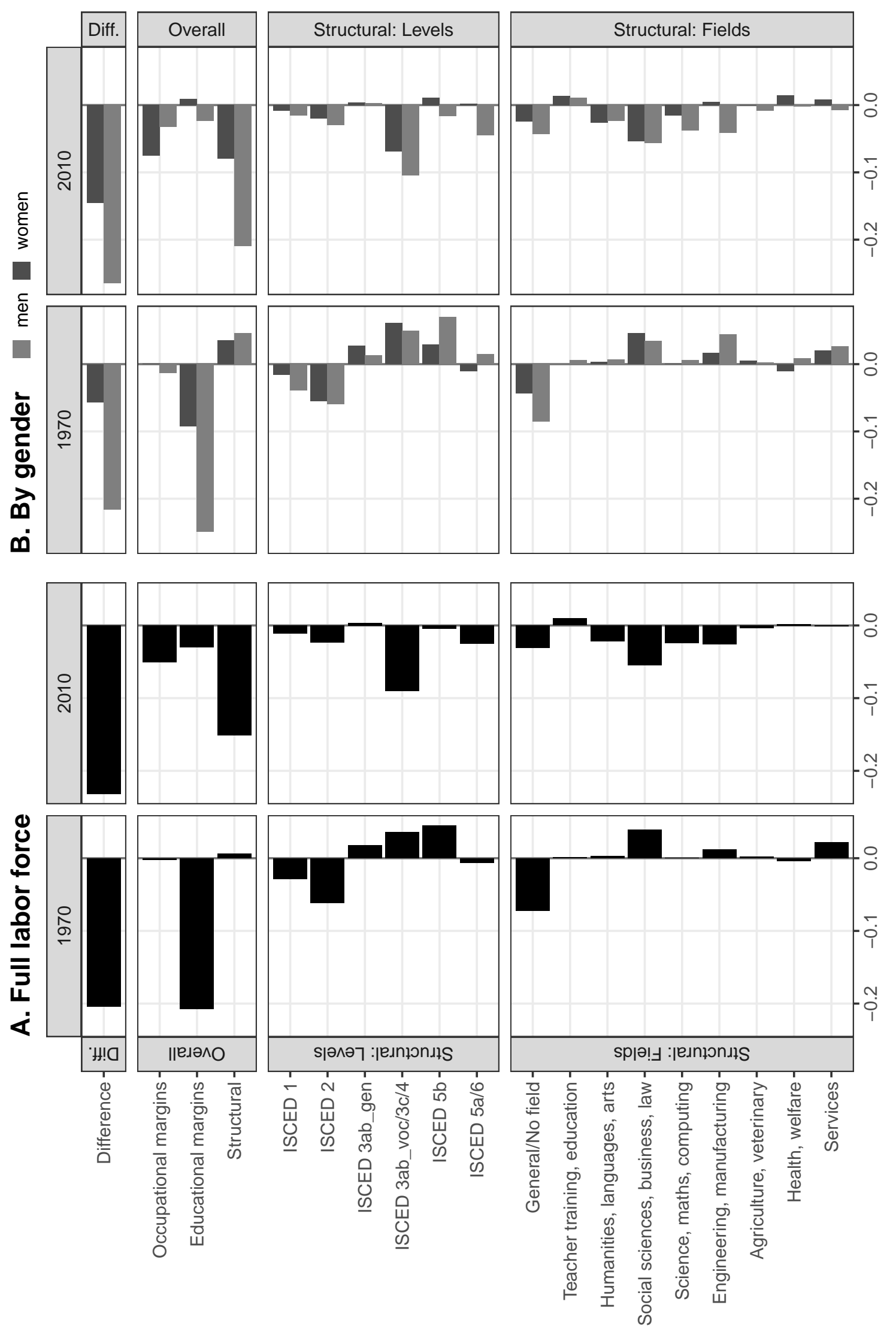

Figure 4: Decomposition of $M$ between countries (differences are France minus Germany). Note: These results are also available as a table in Appendix B. 
second panel from the top (titled "Overall"): "occupational margins," "educational margins," and "structural." As we have described above, the structural change can be further decomposed into the contributions of the 35 level-fields. For an interpretable presentation of the results, we chose to sum those 35 contributions once by level, and once by field. These two decompositions are presented in the third and fourth panel from the top, titled "Structural: Levels" and "Structural: Fields."

Focusing first on the overall decomposition, France's linkage was lower than Germany's in 1970, but this difference is almost completely accounted for by differences in the educational marginal contributions. This means that the stark differences between Germany and France that we observe are mostly a consequence of the differences in educational distributions: In 1970, Germany has many more workers with vocational education than France. Because vocational education links more strongly, Germany's overall linkage is also high. While there are compositional differences, in 1970 the French educational system was not less successful than the German system in providing a close link towards the labor market -it just did so for a smaller share of the labor force. This is the first key result that emerges from the decomposition.

When comparing separately by gender the pattern is similar. A large negative component for the educational margins accounts for a majority of the difference in 1970 for both men and women. What the breakdown by gender makes clear is that France had a small advantage in terms of the structural component: Once we account for the compositional differences, the association between education and occupation was stronger in France than in Germany. Notably, the cross-national difference in educational margins is much more pronounced for men than for women, which is a consequence of the fact that overall linkage differences are much smaller for women than for men.

In 2010, the pattern has changed markedly: While the country differences in linkage remain on the same order of magnitude, they are now to a much lesser degree explained by compositional differences. Instead, about two thirds of the difference in $M$ between Germany and France are now accounted for by structural differences. Given the convergence in educational distributions between Germany and France since 1970 - mostly reflected by the expansion of vocational training in France, with less change in Germany - it is not surprising that the country differences in the educational marginal distributions contribute much less to the overall country difference in $M$ in 2010 than they did in 1970. As in 2010, the linkage differences are smaller for women than for men.

Given the large size of the structural difference between France and Germany, especially in 2010, it is interesting to study where these differences originate. The two further decompositions reveal a considerable heterogeneity by educational levels. First, the most striking result is that in 1970 graduates of ISCED $3 a b \_v o c / 3 c / 4$ and $5 b$ linked more strongly in France than in Germany; in particular, the strength of the link between school and work was higher for upper-secondary vocational graduates in France than in Germany. This again confirms that, in contrast to what MSS argued, the French vocational system did provide a close link between education and occupation. For tertiary education the differences are smaller. We do find that in 2010 the average graduate with a tertiary degree had higher linkage in Germany compared to France, but the difference is small. The main reason why Germany links much stronger in 2010 than in 1970 stems from upper secondary vocational education (ISCED categories $3 a b_{-} v o c / 3 c / 4$ ), which contain both dual training and school-based vo- 
cational education. For women, this category accounts for almost all of the difference, while men also gained a small increase in linkage in higher education (ISCED $5 a / 6$ ).

The decomposition by field of study further shows that the French advantages in 1970 were concentrated in services, business, engineering, and manufacturing. Especially in engineering and manufacturing, men had higher structural linkage than women, which likely reflects the focus of French vocational training on these stereotypically male occupations. In 2010, higher linkage is visible across most fields in Germany, where we can observe higher structural linkage for men in fields such as science, maths, and computing, as well as engineering and manufacturing. These trends likely reflect the continuing strong occupational segregation by gender in both labor markets.

\subsection{Within-country change over time}

The results from the previous section indicate that there was substantial change over time between the two countries, which implies that at least one of the countries must itself have changed over time. Given that the structural differences between Germany and France are much more pronounced in 2010 than 1970, it is possible that Germany has increased its structural linkage, France has lost some of its structural linkage, or a combination of these two processes. To answer this question, we again use eq. (3), but now apply this decomposition to study change within each country over time.

As seen in Figure 1, observed total linkage has increased in both countries at roughly comparable rates. However, the decomposition reveals that the reasons for this increase are starkly different. In Germany, the counterfactual scenario shows that the structure of linkage between educational programs and occupational destinations is almost equally strong in 1970 and 2010. The rise in linkage strength is due to rapid growth in educational credentials that link more strongly to the occupational structure. To be precise, $86 \%$ of the total difference can be explained by changes in the educational and occupational distributions, with the remaining $14 \%$ explained by increasing structural linkage. In both countries, the occupational marginal components are higher for women than for men, which is consistent with the idea of women "catching up" to the occupational attainment of men.

In France, marginal and structural change have different signs, and thus partially offset each other. Due to educational expansion, the change in the marginal educational and occupational distributions point to a large increase in linkage. In fact, if in France only the educational distribution had changed (without influencing structural linkage), France in 2010 would have almost the same total linkage strength as Germany in 2010. However, a large and negative component of structural change offsets a large part of the increase that would be expected from changes in the marginals alone.

Much of the decrease in structural change is due to declines in vocational education $\left(3 a b \_v o c / 3 c / 4\right)$, and women have been much more affected by declines in structural linkage than men. We again also find that most of the change was concentrated in the fields of business, engineering, and manufacturing. In Germany, the small increase in structural linkage is almost entirely due to the male labor force, and especially concentrated in vocational education. If stronger linkage provides benefits in the labor market, both countries have changed in ways that have been unfavorable for women. 

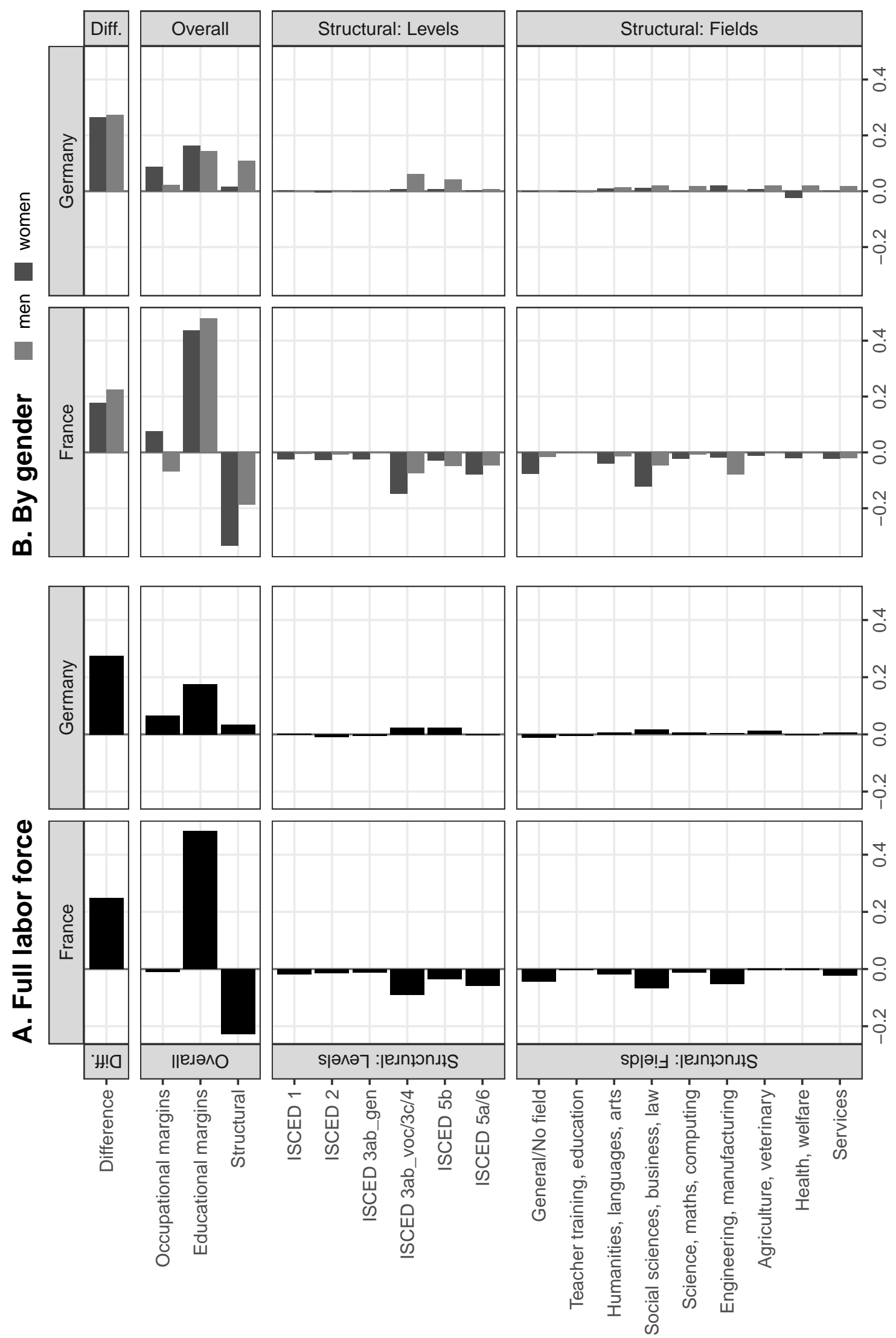

Figure 5: Decomposition of $M$ within countries over time Note: These results are also available as a table in Appendix B. 
Changes in linkage for tertiary education have been small. This is another strong indication that tertiary education is relatively unaffected from developments in the vocational skill formation system. Both over time and between countries, structural differences in tertiary education are small. In this sense, school-to-work linkages in tertiary education are very similar between these two countries and over time, while the differences for vocational education are more pronounced.

\section{Discussion: A historical perspective}

Using data that span the 40 years from 1970 to 2010, we find that an in-depth comparison of the French and German skill formation systems leads to a more complex picture than commonly assumed. The French skill-formation system went through dramatic change in the 40 years between 1970 and 2010. In 1970 France, only a small part of the workforce obtained vocational education, but this training was effective in providing linkage towards specific occupations - even more so than in Germany at the time! This runs counter to the claims made by MSS. Since then, vocational education has rapidly expanded in France, but this training no longer provides such effective linkage. The country differences have reversed: While vocational training in 1970 France was considerably more effective in providing linkage than Germany's vocational training, vocational education in Germany today is more effective than in France. Our findings highlight the importance of distinguishing between margins and structure: In 1970, Germany was much more vocationally oriented than France, but did not provide higher structural linkage. In 2010, the educational distributions of the two countries have converged, but Germany provides stronger structural linkage.

The literature on educational institutions supports these findings and provides an explanation for the decrease in structural linkage in France. It is generally argued that over the past 50 years, France underwent more extensive educational reforms than Germany. The French expansion both at the vocational and the tertiary level was produced by a series of significant reforms - often with explicit reference to the situation in Germany. Charles Day's (2001) history of French vocational and technical education focuses on the institutional fragmentation of general and technical education. Day traces this back to as early as 1890, when the new technical schools were placed under the direction of the ministry of commerce, instead of the ministry of education. This institutional split deepened, and by 1900, the "technical division" had developed a complete educational system on its own, with its own primary, secondary, and tertiary schools. The technical division catered to a selected group of students and aimed to provide high-level vocational training and schooling - a vast difference to Germany's vocational training that, even in the 1970s, can already be characterized as a system "for the masses." The selective nature of vocationally-trained workers in 1970 France aligns with the high amount of structural linkage that we observe for France in 1970, especially for well-trained vocational graduates.

The situation in France is exemplary of the contentious debate about the goals of general versus skilled education, neatly summarized by the opposing poles of the ministries of commerce, favoring specialized education with the backing of industry, and the ministry of education, arguing for a civic ideal of education. The integration of the two systems, while proposed several times in the course of the 20th century, did not occur until 1960. Since 
then, various reforms followed that expanded vocational education at different educational levels. Of special note is the "loi Jospin" from 1989, named after the education minister, which formulated the goal that "all young people reach a recognized level of training" (n.a. 1996, p. 49).

Meanwhile, France continued to lack the "decentralized cooperation" between unions, employers, and the state that characterized Germany (Hall and Soskice 2001). It could well be that this lack of decentralized cooperation created imbalances in the supply and demand of workers who were graduating from the expanding specialized educational programs in France. The weaker regulation might also have given French employers greater flexibility in hiring workers whose credentials were not the natural match to the jobs but who otherwise were judged by the employers to be good fits. Either or both of these mechanisms could explain the combination of growing composition-based linkage strength and declining structural-based linkage strength in France.

The contentious history of educational reforms in France contrasts markedly with the German situation (Brauns et al. 1999). The basic system in Germany has been in place since the late 19th century, and despite the two world wars and the political upheavals, has changed only little (Thelen 2004). The German arrangement of vocational ('dual') training has existed since the late 19th century, and relies on close coordination between industry and the educational system. Reforms were planned in Germany as well, especially by the socialdemocratic governments (1969-1982), and were aimed to remove early tracking or replace some of the vocational training with more general, school-based training. However, these reforms were not implemented. This is clearly visible in our results, which show that in Germany almost no structural change can be observed.

\section{Conclusions}

We investigated how educational systems match workers to the labor market and how this has changed across two countries that are often seen as ideal-types: France and Germany. We summarize our findings in three main points.

First, school-to-work linkages have increased over time in both France and Germany. This means that occupations have become more educationally homogeneous, and educational pathways typically lead to a smaller set of occupations. In Germany, the increase in linkage strength was achieved through a relatively modest quantitative expansion in both vocational and tertiary education, but this expansion was not paired with substantial reforms that would have altered school-to-work linkages. In France on the other hand, we find a large increase in the number of vocational and tertiary graduates. This increase was accompanied by a decline in structural linkage. The decline was especially pronounced for vocational graduates, and was greater for women than for men in both countries. While more students in France enrolled in vocational programs, this came at the cost of the linkage strength of these programs, as students increasingly dispersed across different occupations.

Our results underscore the importance of attending to structural as well as compositional differences in conceptualizing educational systems across countries and over time. This distinction is also important for policymakers and the debate about general vs. vocational education, more generally. The "success" of vocational programs is often defined by a strong 
linkage to the labor market (indicated, for instance, by a relative ease in entering the labor market). However, faced with changing labor markets and skill requirements, some have called into question the benefits of strong linkage (Hanushek et al. 2017). Because the linkage approach shifts the focus from national education systems to individual educational pathways, it can contribute to this debate by studying the effects of weakly and strongly linking programs on workers' career outcomes (Forster et al. 2016).

Second, we find that the German vocational system in 1970 was not - on averagesubstantially more efficient in allocating graduates to specific occupations than the French skill formation system. This finding is a major departure from the results presented by MSS that have been reinforced by other studies. The main reason that Germany was portrayed as a vocational system is because more students were enrolled in secondary-level vocational programs in Germany than in France. While there are clear differences in the rates of vocational education, the two countries were similar in the extent to which particular educational programs created a strong link to the labor market.

In particular, we find that some of MSS's conclusions are not warranted when the whole of the labor force, including women, is taken into account. We thus emphasize that the historical study of skill-formation systems needs to pay attention to the role of gender. Country differences are more pronounced when only men are considered. For female workers, France and Germany were already very similar in the 1970s and have remained similar since then. This may reflect the common experiences of women in both France and Germany, slowly gaining access to the labor market and higher education. Vocational policy is often especially focused on manufacturing and business degrees, which were historically geared towards men. The fact that many classifications of skill-formation systems are based only on the male workforce affects how we think about skill formation systems. We show that ignoring the female workforce has large consequences for today's conception of skill formation systems, particularly because a large share of educational expansion is caused by an increase in female enrollment in (higher) education.

Our results raise the question whether the cross-national classifications of skill formation systems that are dominant in the current literature do justice to actual cross-national differences. We believe this not to be the case. When looking more closely into how school-to-work linkages are established, countries might be similar on some aspects (structural linkage), but differ on others (composition of workers across the programs). Moreover, the differences within countries are as large or larger than differences between countries. The characterization of skill-formation systems as qualificational or organizational might thus be even less appropriate when a large fraction of the labor force has attained tertiary education. Future research should move beyond treating countries as entities with homogeneous skill formation systems that are stable over time.

\section{Appendix A: Full decomposition}

The changes in the marginal component can be decomposed into two components for the educational and occupational distribution, respectively. To do this, we consider all the ways in which either marginal component can be eliminated. For this, we need to consider all possible combinations between educational marginals, occupational marginals, and odds ra- 
tios from both $t_{1}$ and $t_{2}$. We write $M(G ; J ; O)$ to identify the $M$ that is calculated based on the educational marginals from $G$, the occupational marginals from $J$, and the odds ratios from $O$. For instance, $M\left(t_{1}\right)=M\left(t_{1} ; t_{1} ; t_{1}\right)$ and $M\left(t_{1}^{\prime}\right)=M\left(t_{2} ; t_{2} ; t_{1}\right)$. Given all possible combinations, there are eight unique matrices, including the two unaltered ones. This decomposition thus requires six IPF procedures. The decomposition relies on averaging all possible elimination strategies. To quantify the effect of marginal change in the educational distribution, there are four possible elimination strategies:

$$
\begin{aligned}
\Delta_{\text {education }} & =\frac{1}{4}\left(M\left(t_{2} ; t_{1} ; t_{1}\right)-M\left(t_{1} ; t_{1} ; t_{1}\right)\right)+\frac{1}{4}\left(M\left(t_{2} ; t_{2} ; t_{1}\right)-M\left(t_{1} ; t_{2} ; t_{1}\right)\right) \\
& +\frac{1}{4}\left(M\left(t_{2} ; t_{2} ; t_{2}\right)-M\left(t_{1} ; t_{2} ; t_{2}\right)\right)+\frac{1}{4}\left(M\left(t_{2} ; t_{1} ; t_{2}\right)-M\left(t_{1} ; t_{1} ; t_{2}\right)\right)
\end{aligned}
$$

Within each subtraction, only the educational margins are changed, with the other two factors held constant. The term $\Delta_{\text {occupation }}$ is defined equivalently, and the sum of $\Delta_{\text {education }}$ and $\Delta_{\text {occupation }}$ equals $\Delta_{\text {marginal }}$ from (3).

The term for the structural component admits a straightforward decomposition based on local segregation scores. The key property that these decompositions exploit is that $p_{\cdot g}^{t_{2}}=p_{\cdot g}^{t_{1}^{\prime}}$, $p_{j}^{t_{2}}=p_{j}^{t_{1}^{\prime}}, p_{\cdot g}^{t_{1}}=p_{. g}^{t_{2}^{\prime}}$, and $p_{j}^{t_{1}}=p_{j}^{t_{2}^{\prime}}$, i.e. the equivalence of the margins. We can thus write:

$$
\begin{aligned}
\Delta_{\text {structural }} & =\frac{1}{2}\left(M\left(t_{2}\right)-M\left(t_{1}^{\prime}\right)\right)+\frac{1}{2}\left(M\left(t_{2}^{\prime}\right)-M\left(t_{1}\right)\right) \\
& =\sum_{g=1}^{G}\left(\frac{1}{2} p_{\cdot g}^{t_{2}}\left[L_{g}\left(t_{2}\right)-L_{g}\left(t_{1}^{\prime}\right)\right]+\frac{1}{2} p_{\cdot g}^{t_{1}}\left[L_{g}\left(t_{2}^{\prime}\right)-L_{g}\left(t_{1}\right)\right]\right) \\
& =\sum_{g=1}^{G}\left(\frac{1}{2} p_{\cdot g}^{t_{2}}\left[\sum_{j=1}^{J} p_{j \mid g}^{t_{2}} \ln \frac{p_{j \mid g}^{t_{2}}}{p_{j .}^{t_{2}}}-p_{j \mid g}^{t_{1}^{\prime}} \ln \frac{p_{j \mid g}^{t_{1}^{\prime}}}{p_{j \cdot}^{t_{2}}}\right]+\frac{1}{2} p_{\cdot g}^{t_{1}}\left[\sum_{j=1}^{J} p_{j \mid g}^{t_{2}^{\prime}} \ln \frac{p_{j \mid g}^{t_{2}^{\prime}}}{p_{j .}^{t_{1}}}-p_{j \mid g}^{t_{1}} \ln \frac{p_{j \mid g}^{t_{1}}}{p_{j \cdot}^{t_{1}}}\right]\right)
\end{aligned}
$$

where $L_{g}(\mathbf{X})$ refers to the local segregation score for educational degree $g$ in matrix $\mathbf{X}$. The difference in structural segregation can thus be attributed solely to differences in the conditional probabilities, holding the marginals constant. 


\section{Appendix B: Decomposition tables}

\begin{tabular}{|c|c|c|c|c|c|c|c|c|c|c|c|c|}
\hline & \multicolumn{4}{|c|}{ All workers } & \multicolumn{4}{|c|}{ Male } & \multicolumn{4}{|c|}{ Female } \\
\hline & 1970 & $(\%)$ & 2010 & $(\%)$ & 1970 & $(\%)$ & 2010 & $(\%)$ & 1970 & $(\%)$ & 2010 & $(\%)$ \\
\hline M Germany & 0.64 & & 0.92 & & 0.59 & & 0.87 & & 0.56 & & 0.82 & \\
\hline M France & 0.44 & & 0.68 & & 0.38 & & 0.60 & & 0.50 & & 0.68 & \\
\hline Difference & -0.20 & $(100)$ & -0.23 & $(100)$ & -0.22 & $(100)$ & -0.27 & $(100)$ & -0.06 & $(100)$ & -0.15 & $(100)$ \\
\hline Total marginal & -0.21 & $(103)$ & -0.08 & $(35)$ & -0.26 & $(121)$ & -0.06 & $(21)$ & -0.09 & (161) & -0.07 & $(45)$ \\
\hline Occupational margins & -0.00 & (1) & -0.05 & $(22)$ & -0.01 & (6) & -0.03 & (12) & 0.00 & $(-0)$ & -0.08 & $(52)$ \\
\hline Educational margins & -0.21 & $(102)$ & -0.03 & (13) & -0.25 & (115) & -0.02 & (9) & -0.09 & $(162)$ & 0.01 & $(-6)$ \\
\hline Total structural & 0.01 & $(-3)$ & -0.15 & (65) & 0.05 & $(-21)$ & -0.21 & (79) & 0.03 & $(-61)$ & -0.08 & $(55)$ \\
\hline \multicolumn{13}{|l|}{ by levels } \\
\hline ISCED 1 & -0.03 & (14) & -0.01 & (5) & -0.04 & (18) & -0.02 & (6) & -0.02 & (28) & -0.01 & (6) \\
\hline ISCED 2 & -0.06 & (30) & -0.02 & (10) & -0.06 & (27) & -0.03 & (11) & -0.05 & (96) & -0.02 & (13) \\
\hline ISCED 3ab_gen & 0.02 & $(-9)$ & 0.00 & $(-2)$ & 0.01 & $(-6)$ & 0.00 & $(-1)$ & 0.03 & $(-47)$ & 0.00 & $(-2)$ \\
\hline ISCED 3ab_voc/3c/4 & 0.04 & $(-18)$ & -0.09 & (39) & 0.05 & $(-23)$ & -0.10 & $(40)$ & 0.06 & $(-108)$ & -0.07 & $(47)$ \\
\hline ISCED 5b & 0.05 & $(-22)$ & -0.00 & (2) & 0.07 & $(-32)$ & -0.02 & (6) & 0.03 & $(-51)$ & 0.01 & $(-8)$ \\
\hline ISCED $5 \mathrm{a} / 6$ & -0.01 & (3) & -0.03 & (11) & 0.01 & $(-7)$ & -0.05 & (17) & -0.01 & (18) & 0.00 & $(-2)$ \\
\hline \multicolumn{13}{|l|}{ by fields } \\
\hline General/No field & -0.07 & $(35)$ & -0.03 & (13) & -0.09 & (39) & -0.04 & (16) & -0.04 & (77) & -0.02 & (17) \\
\hline Teacher training, education & 0.00 & $(-0)$ & 0.01 & $(-4)$ & 0.01 & $(-3)$ & 0.01 & $(-4)$ & & & 0.01 & $(-9)$ \\
\hline Humanities, languages, arts & 0.00 & $(-1)$ & -0.02 & (9) & 0.01 & $(-3)$ & -0.02 & (9) & 0.00 & $(-5)$ & -0.03 & (18) \\
\hline Social sciences, business, law & 0.04 & $(-19)$ & -0.05 & (24) & 0.03 & $(-16)$ & -0.06 & (21) & 0.05 & $(-80)$ & -0.05 & (37) \\
\hline Science, maths, computing & 0.00 & $(-0)$ & -0.02 & (10) & 0.01 & $(-3)$ & -0.04 & (14) & 0.00 & $(-0)$ & -0.02 & (10) \\
\hline Engineering, manufacturing & 0.01 & $(-6)$ & -0.03 & (11) & 0.04 & $(-21)$ & -0.04 & (16) & 0.02 & $(-29)$ & 0.01 & $(-4)$ \\
\hline Agriculture, veterinary & 0.00 & $(-1)$ & -0.00 & (2) & 0.00 & $(-1)$ & -0.01 & (3) & 0.00 & $(-8)$ & -0.00 & (0) \\
\hline Health, welfare & -0.00 & $(2)$ & 0.00 & $(-1)$ & 0.01 & $(-4)$ & -0.00 & (1) & -0.01 & (18) & 0.01 & $(-10)$ \\
\hline Services & 0.02 & $(-11)$ & -0.00 & (1) & 0.03 & $(-12)$ & -0.01 & (3) & 0.02 & $(-36)$ & 0.01 & $(-6)$ \\
\hline
\end{tabular}

Table 3: Decomposition of $M$ between countries (differences are France minus Germany). 


\begin{tabular}{|c|c|c|c|c|c|c|c|c|c|c|c|c|}
\hline & \multicolumn{4}{|c|}{ All workers } & \multicolumn{4}{|c|}{ Male } & \multicolumn{4}{|c|}{ Female } \\
\hline & 1970 & $(\%)$ & 2010 & $(\%)$ & 1970 & $(\%)$ & 2010 & $(\%)$ & 1970 & $(\%)$ & 2010 & $(\%)$ \\
\hline M 1970 & 0.64 & & 0.44 & & 0.59 & & 0.38 & & 0.56 & & 0.50 & \\
\hline M 2010 & 0.92 & & 0.68 & & 0.87 & & 0.60 & & 0.82 & & 0.68 & \\
\hline Difference & 0.28 & $(100)$ & 0.25 & $(100)$ & 0.27 & $(100)$ & 0.23 & $(100)$ & 0.27 & $(100)$ & 0.18 & $(100)$ \\
\hline Total marginal & 0.24 & $(88)$ & 0.47 & $(192)$ & 0.17 & $(61)$ & 0.41 & $(183)$ & 0.25 & $(94)$ & 0.51 & $(290)$ \\
\hline Occupational margins & 0.07 & (24) & -0.01 & $(-4)$ & 0.02 & $(8)$ & -0.07 & $(-30)$ & 0.09 & (33) & 0.08 & (43) \\
\hline Educational margins & 0.18 & (64) & 0.48 & (195) & 0.14 & $(52)$ & 0.48 & (213) & 0.16 & (61) & 0.44 & $(247)$ \\
\hline Total structural & 0.03 & (12) & -0.23 & $(-92)$ & 0.11 & (39) & -0.19 & $(-83)$ & 0.02 & (6) & -0.33 & $(-190)$ \\
\hline \multicolumn{13}{|l|}{ by levels } \\
\hline ISCED 1 & 0.00 & (1) & -0.02 & $(-7)$ & 0.00 & (1) & -0.01 & $(-2)$ & 0.00 & (1) & -0.02 & $(-14)$ \\
\hline ISCED 2 & -0.01 & $(-3)$ & -0.01 & $(-6)$ & -0.00 & $(-1)$ & -0.01 & $(-3)$ & -0.00 & $(-2)$ & -0.03 & $(-15)$ \\
\hline ISCED 3ab_gen & -0.00 & $(-2)$ & -0.01 & $(-5)$ & -0.00 & $(-1)$ & -0.00 & $(-2)$ & -0.00 & $(-1)$ & -0.03 & $(-14)$ \\
\hline ISCED 3ab_voc/3c/4 & 0.02 & (9) & -0.09 & $(-37)$ & 0.06 & $(22)$ & -0.08 & $(-34)$ & 0.01 & (3) & -0.15 & $(-84)$ \\
\hline ISCED 5b & 0.02 & (9) & -0.04 & $(-14)$ & 0.04 & $(16)$ & -0.05 & $(-22)$ & 0.01 & (3) & -0.03 & $(-16)$ \\
\hline ISCED $5 \mathrm{a} / 6$ & -0.00 & $(-1)$ & -0.06 & $(-23)$ & 0.01 & $(3)$ & -0.05 & $(-21)$ & 0.00 & (1) & -0.08 & $(-45)$ \\
\hline \multicolumn{13}{|l|}{ by fields } \\
\hline General/No field & -0.01 & $(-4)$ & -0.04 & $(-18)$ & -0.00 & $(-1)$ & -0.02 & $(-7)$ & -0.00 & $(-1)$ & -0.08 & $(-44)$ \\
\hline Teacher training, education & -0.01 & $(-2)$ & -0.00 & $(-1)$ & -0.00 & $(-2)$ & -0.00 & $(-1)$ & -0.00 & $(-1)$ & & \\
\hline Humanities, languages, arts & 0.01 & $(2)$ & -0.02 & $(-7)$ & 0.01 & $(5)$ & -0.01 & $(-6)$ & 0.01 & $(3)$ & -0.04 & $(-23)$ \\
\hline Social sciences, business, law & 0.02 & (6) & -0.07 & $(-27)$ & 0.02 & (8) & -0.05 & $(-21)$ & 0.01 & (4) & -0.12 & $(-69)$ \\
\hline Science, maths, computing & 0.01 & $(2)$ & -0.01 & $(-5)$ & 0.02 & (6) & -0.01 & $(-3)$ & -0.00 & $(-0)$ & -0.02 & $(-13)$ \\
\hline Engineering, manufacturing & 0.00 & (1) & -0.05 & $(-21)$ & 0.01 & $(2)$ & -0.08 & $(-35)$ & 0.02 & (8) & -0.02 & $(-10)$ \\
\hline Agriculture, veterinary & 0.01 & $(5)$ & -0.00 & $(-2)$ & 0.02 & (7) & -0.00 & $(-1)$ & 0.01 & (2) & -0.01 & $(-7)$ \\
\hline Health, welfare & -0.00 & $(-1)$ & -0.00 & $(-2)$ & 0.02 & (7) & 0.00 & $(0)$ & -0.02 & $(-9)$ & -0.02 & $(-12)$ \\
\hline Services & 0.01 & $(2)$ & -0.02 & $(-9)$ & 0.02 & (6) & -0.02 & $(-9)$ & -0.00 & $(-1)$ & -0.02 & $(-13)$ \\
\hline
\end{tabular}

Table 4: Decomposition of $M$ within countries over time

\section{About the Authors}

Benjamin Elbers is a Ph.D. candidate in sociology at Columbia University. His research interests include segregation methodology, education, and labor markets. Recent articles have appeared in Management Science and Compare.

Thijs Bol is an associate professor in the Department of Sociology at the University of Amsterdam. His research interests are in social stratification and inequality in education, the labor market, and science. Recent publications include "School-to-Work Linkages, Educational Mismatches, and Labor Market Outcomes" (American Sociological Review, 2019).

Thomas A. DiPrete is Giddings Professor of Sociology at Columbia University. His research interests include the structure of inequality, the causes of inequality trends especially in elite labor markets, educational performance and attainment, and the school-to-work transition and how educational and labor market institutions affect the quality of linkage between school credentials and occupations. 


\section{References}

Allmendinger, Jutta (1989). "Educational Systems and Labor Market Outcomes". In: European Sociological Review 5.3, pp. 231-250.

Benavot, Aaron (1983). "The Rise and Decline of Vocational Education". In: Sociology of Education 56.2, pp. 63-76.

Bol, Thijs, Christina Ciocca Eller, H. G Van De Werfhorst, and Thomas A DiPrete (2019). "School-to-Work Linkages, Educational Mismatches, and Labor Market Outcomes". en. In: American Sociological Review 84.2, pp. 275-307.

Bol, Thijs and Herman G Van de Werfhorst (2013). "Educational Systems and the Tradeoff between Labor Market Allocation and Equality of Educational Opportunity". In: Comparative Education Review 57.2, pp. 285-308.

Brauns, Hildegard, Susanne Steinmann, Annick Kieffer, and Catherine Marry (1999). "Does Education Matter? France and Germany in Comparative Perspective". In: European Sociological Review 15.1, pp. 61-89.

Breen, Richard (2005). "Explaining Cross-National Variation in Youth Unemployment: Market and Institutional Factors". In: European Sociological Review 21.2, pp. 125-134.

Bundesinstitut für Berufsbildung [BIBB] (2006). BIBB/BAuA-Erwerbstätigenbefragung 2006.

Day, Charles R. (2001). Schools and Work. Technical and Vocational Education in France since the Third Republic. Montreal \& Kingston: McGill-Queen's University Press.

DiPrete, Thomas A., Thijs Bol, Christina Ciocca Eller, and Herman G. van de Werfhorst (2017). "School-to-Work Linkages in the United States, Germany, and France". In: American Journal of Sociology 122.6, pp. 1869-1938.

Elbers, Benjamin (2020). A Method for Studying Difference in Segregation Levels Across Time and Space. DOI: 10.31235/osf .io/ya7zs.

Eurostat (n.d.). European Labor Force Survey, 2005-2010.

Forster, Andrea G., Thijs Bol, Van De Werfhorst, and Herman G (2016). "Vocational Education and Employment over the Life Cycle". In: Sociological Science 3, pp. 473-494.

Goux, Dominique and Eric Maurin (1998). "From Education to First Job: The French Case". In: From School to Work: A Comparative Study of Educational Qualifications and Occupational Destinations. Ed. by Yossi Shavit and Walter Müller. Oxford: Clarendon Press.

Hall, Peter A. and David Soskice (2001). Varieties of Capitalism: The Institutional Foundations of Comparative Advantage. Oxford University Press.

Haller, Max, Wolfgang König, Peter Krause, and Karin Kurz (1985). "Patterns of Career Mobility and Structural Positions in Advanced Capitalist Societies". In: American Sociological Review 50, pp. 579-603.

Hanushek, Eric A., Guido Schwerdt, Ludger Woessmann, and Lei Zhang (2017). "General Education, Vocational Education, and Labor-Market Outcomes over the Lifecycle". In: Journal of Human Resources 52.1, pp. 48-87.

INSEE/ADISP-CMH (n.d.[a]). Enquêtes Emploi, série 1990-2002.

- (n.d.[b]). Formation, qualification professionnelle (FQP), 1970 and 1985.

Karmel, T. and M. Maclachlan (1988). "Occupational Sex Segregation - Increasing or Decreasing?" In: Economic Record 64.3, pp. 187-195.

Kerckhoff, Alan C. (1995). "Institutional arrangements and stratification processes in industrial societies". In: Annual review of sociology 21.1, pp. 323-347. 
König, Wolfgang and Walter Müller (1986). "Educational systems and labour markets as determinants of worklife mobility in France and West Germany: a comparison of men's career mobility, 1965-1970". In: European Sociological Review 2.2, pp. 73-96.

Marry, Catherine, Annick Kieffer, Hildegard Brauns, and Susanne Steinmann (1998). "FranceAllemagne: Inégales Avancées Des Femmes: Évolutions Comparées de l'éducation et de l'activité Des Femmes de 1971 à 1991". In: Revue française de sociologie 39.2, pp. 353389.

Maurice, Marc, François Sellier, and Jean-Jacques Silvestre (1986). The social foundations of industrial power: a comparison of France and Germany. Cambridge, Mass: MIT Press.

Mora, Ricardo and Javier Ruiz-Castillo (2011). "Entropy-Based Segregation Indices". In: Sociological Methodology 41.1, pp. 159-194.

Müller, Walter and Markus Gangl (2003). Transitions from Education to Work in Europe. Oxford University Press.

Müller, Walter and Yossi Shavit (1998). "The institutional embeddedness of the stratification process: A comparative study of qualifications and occupations in thirteen countries". In: From school to work: A comparative study of educational qualifications and occupational destinations, pp. 1-48.

Müller, Walter, Susanne Steinmann, and Renate Ell (1998). "Education and labour-market entry in Germany". In: From school to work. A comparative study of educational qualifications and occupational destinations. Ed. by Yossi Shavit and Walter Müller, pp. 143188.

n.a. (1996). "The 'Loi Jospin'. The Education Framework Act 1989 (Extracts)". In: Education in France. Continuity and Change in the Mitterrand Years, 1981-1995. Ed. by Anne Corbett and Bob Moon. London and New York: Routledge, pp. 49-55.

OECD European Union, UNESCO Institute for Statistics (2015). ISCED 2011 Operational Manual: Guidelines for Classifying National Education Programmes and Related Qualifications. Tech. rep. OECD Publishing.

RDC of the Federal Statistical Office and Statistical Offices of the Länder (n.d.). Census of 1970 and 1987 (Public Use Files).

Shavit, Yossi and Walter Müller (1998). From School to Work. A Comparative Study of Educational Qualifications and Occupational Destinations. Oxford: Oxford University Press.

Theil, Henri and Anthony J. Finizza (1971). "A Note on the Measurement of Racial Integration of Schools by Means of Informational Concepts". In: Journal of Mathematical Sociology 1.2, pp. 187-193.

Thelen, Kathleen A. (2004). How Institutions Evolve: The Political Economy of Skills in Germany, Britain, the United States, and Japan. Cambridge: Cambridge University Press.

Wolbers, Maarten HJ (2007). "Patterns of Labour Market Entry A Comparative Perspective on School-to-Work Transitions in 11 European Countries". In: Acta sociologica 50.3, pp. 189-210. 